\title{
The effect of dietary modification and hyperglycaemia on gastric emptying and gastric inhibitory polypeptide (GIP) secretion
}

\author{
BY L. M. MORGAN ${ }^{1}$, J. A. T. TREDGER ${ }^{1}$, S. M. HAMPTON ${ }^{1}$, \\ A. P. FRENCH ${ }^{2}$, J. C. F. PEAKE ${ }^{2}$ AND V. MARKS ${ }^{1}$ \\ ${ }^{1}$ Department of Biochemistry, University of Surrey, Guildford, Surrey GU2 $5 X H$ \\ ${ }^{2}$ Department of Medical Physics, St Luke's Hospital, Guildford, Surrey
}

(Received 24 July 1987 - Accepted 19 February 1988)

\begin{abstract}
1. Five healthy volunteers whose usual fat and energy intakes were moderately high (fat intake 155 (SE 11) $\mathrm{g} / \mathrm{d}$; energy intake 13683 (SE 909) $\mathrm{kJ} / \mathrm{d}$ ) were given on two separate occasions (a) $96 \mathrm{~g}$ fat and (b) $96 \mathrm{~g}$ fat and intravenous (IV) glucose ( $250 \mathrm{~g}$ glucose $/ 1 ; 100 \mathrm{ml}$ followed by a $2 \mathrm{ml} / \mathrm{min}$ infusion for $180 \mathrm{~min}$ ).

2. Subjects continued on a low-fat diet for $35 \mathrm{~d}$ (fat intake 25 (SE 4) g/d; energy intake 6976 (SE 539) kJ/d) and the tests repeated.

3. The gastric inhibitory polypeptide (GIP) response to oral fat was significantly attenuated by IV glucose whilst subjects were consuming their normal diets and the GIP response to fat alone was significantly diminished during the low-fat diet. Post-prandial plasma triglycerides, light scattering indices (LSI; an index of post-prandial chylomicronaemia) and paracetamol levels paralleled the integrated GIP responses on both normal and low-fat diets

4. The study of oral fat with or without glucose was repeated on seven further volunteers consuming their usual diet, substituting $10 \mathrm{MBq}^{98} \mathrm{Tc}^{\mathrm{m}}$-labelled tin colloid for the paracetamol to investigate the rate of gastric emptying by radionuclide imaging.

5. Plasma GIP, insulin, triglyceride and LSI levels were similar to those found in the first study. IV glucose almost doubled the gastric emptying time of the oral fat load (half emptying time ( $\left.t_{\frac{1}{2}}\right) 148$ (SE 11 ) min after fat alone and 224 (SE 18) min after fat and IV glucose). Post-prandial plasma motilin levels were significantly depressed by IV glucose.

6. We conclude that (a) the GIP response to oral fat is attenuated both by IV glucose and by a low-fat diet, (b) the delay in gastric emptying induced by IV glucose may be partly responsible for the diminished GIP response to oral fat when IV glucose is infused, (c) it is possible that some of the changes observed with IV glucose are mediated via changes in motilin.
\end{abstract}

The gastrointestinal hormone gastric inhibitory polypeptide (GIP) is a potent stimulator of insulin secretion (Brown et al. 1975) and is currently thought to be one of the main components of the entero-insular axis. We have previously shown that GIP secretion can be influenced by diet. A high-fat diet increases fat-stimulated GIP secretion in rats and abolishes the inhibition of exogenous insulin on fat-stimulated GIP release in both rats and man (Hampton et al. 1983; Morgan et al. 1983). An increased GIP response to oral glucose is also seen after a $28 \mathrm{~d}$ period on a high-fat diet in human volunteers (Morgan et al. 1984). Exaggerated GIP responses and a consequently overactive entero-insular axis could be implicated, at least in part, in the development of the hyperinsulinaemia associated with various disease states in which dietary factors also play a part, for example, maturity-onset diabetes and obesity. Exaggerated GIP responses have been observed after a mixed meal in obese subjects (Ebert et al. 1976), but these are reversed by $5 \mathrm{~d}$ of energy restriction (Willms et al. 1978). However, recent evidence suggests that changes in the rate of gastric emptying in obesity may explain the observed differences in GIP secretion (Ebert \& Creutzfeldt, 1987).

Hyperinsulinaemia is implicated as a risk factor in the development of cardiovascular disease (Stout, 1982). Current epidemiological research on Western diets and the incidence of cardiovascular disease has led to recommendations to reduce dietary fat intakes (National Advisory Committee on Nutrition Education, 1983). We have therefore 
investigated the effect of fat and energy restriction on fat-stimulated GIP secretion and the feed-back control of hyperinsulinaemia on GIP release in human subjects. Gastric emptying rates were initially estimated by adding paracetamol to the test meal and monitoring its appearance in plasma as a simple and inexpensive screening test which correlates well with the measurement of gastric emptying by radionuclide imaging (Holt $e t$ al. 1979). In a separate experiment they were verified whilst subjects were consuming their normal diets by radionuclide imaging using ${ }^{99} \mathrm{Tc}^{\mathrm{m}}$, by substituting ${ }^{99} \mathrm{Tc}^{\mathrm{m}}$-labelled tin colloid mixed into the meal for the paracetamol.

\section{MATERIALS AND METHODS}

Study 1

Five healthy volunteers aged between 19 and 27 years (mean 23 years), who were within $20 \%$ ideal body-weight (Metropolitan Life Insurance Company, 1959), participated in the study. Subjects' usual daily fat intake was initially assessed by dietary-recall method, obtained by personal interview. After a 2-week period in which subjects kept to their usual diet, they were instructed to consume a low-fat diet for $35 \mathrm{~d}$. In order to maintain their usual energy intake they were encouraged to eat foods with a high-carbohydrate, low-fat content. For $14 \mathrm{~d}$ before and whilst adhering to the low-fat regimen, all subjects recorded their daily food intake on two weekdays and the weekend of each week. The food intakes were analysed using a computerized diet program (Gamble et al. 1980). Subjects underwent investigation on four separate occasions, two before and two during the $35 \mathrm{~d}$ dietary modification. After an overnight fast, intravenous (IV) cannulas were inserted, one into an anticubital vein for the collection of venous blood, the other into a dorsal hand vein, heated to approximately $55^{\circ}$ by means of an electric heating blanket. This vein was used for the collection of 'arterialized' blood. Subjects consumed the following test meals, in random order, 1 week apart, before and on weeks 4 or 5 of the period of dietary modification.

Test meal 1 . This consisted of fat whilst receiving IV saline $(9 \mathrm{~g}$ sodium chloride/1): $96 \mathrm{~g}$ fat, in the form of $200 \mathrm{ml}$ double cream, was consumed followed by $1.5 \mathrm{~g}$ soluble paracetamol in $75 \mathrm{ml}$ water. Simultaneously, $100 \mathrm{ml}$ saline was injected into an anticubital vein followed by a $2 \mathrm{ml} / \mathrm{min}$ infusion of saline continuously throughout the $3 \mathrm{~h}$ study period.

Test meal 2. This consisted of oral fat whilst receiving IV glucose. The procedure was similar to that for test meal 1 but with substitution of $250 \mathrm{~g}$ glucose $/ 1$ for the saline. The total amount of glucose infused per subject was $115 \mathrm{~g}$.

Chemical analyses. Plasma glucose concentrations were measured in all arterialized and venous blood samples using an automated glucose oxidase $(E C$ 1.1.3.4) technique. Plasma immunoreactive insulin and GIP (Morgan et al. 1978) concentrations were measured in venous blood by double antibody techniques using antisera supplied by Guildhay Antisera (University of Surrey, Guildford). The sensitivity of the insulin assay was $2.5 \mathrm{mU} / 1$ and of the GIP assay $110 \mathrm{ng} / 1$; inter-assay coefficients of variation were 7.4 and $11 \%$ respectively. Venous plasma triglyceride concentrations were measured using a fully enzymic u.v. kit (Boehringer, Mannheim, W. Germany), and plasma light scattering indices (LSI) measured using a Thorpe micronephelometer (Thorpe Instruments, Cheshire), as an index of post-prandial chylomicronaemia. Plasma paracetamol was measured by high-performance liquid chromatography using $100 \times 5 \mathrm{~mm}$ ODS $\left(\mathrm{C}_{18}\right)$ column and a running solvent consisting of $0.05 \mathrm{M}$-sodium acetate $(\mathrm{pH} \mathrm{4.6)}$ in methanol $(80: 20, \mathrm{v} / \mathrm{v})$. Benzoic acid was used as an internal standard and the eluate monitored with a u.v. detector at $249 \mathrm{~nm}$. 
Table 1. Daily fat and energy intakes of human subjects when consuming their usual diets and the low-fat diet*

(Mean values with their standard errors)

\begin{tabular}{|c|c|c|c|c|c|c|}
\hline \multirow[b]{2}{*}{ Diet } & \multicolumn{2}{|c|}{$\begin{array}{l}\text { Fat intake } \\
(\mathrm{g} / \mathrm{d})\end{array}$} & \multicolumn{2}{|c|}{$\begin{array}{l}\text { Energy intake } \\
(\mathrm{kJ} / \mathrm{d})\end{array}$} & \multicolumn{2}{|c|}{$\begin{array}{l}\text { Energy from fat } \\
(\%)\end{array}$} \\
\hline & Mean & $\mathrm{SE}$ & Mean & SE & Mean & $\mathrm{SE}$ \\
\hline Normal & 155 & 11 & 13683 & 909 & 43 & $2 \cdot 1$ \\
\hline Low-fat & 25 & 4 & 6976 & 539 & $13 \cdot 4$ & 2.0 \\
\hline
\end{tabular}

* For details, see p. 30.

Study 2

Seven healthy volunteers aged between 22 and 42 years (mean 27 years), all within $20 \%$ ideal body-weight, participated. In the study the seven subjects underwent the oral fat with or without glucose protocols (test meals 1 and 2) of study 1 whilst on a normal diet (fat intake 82 (SE 12) $\mathrm{g} / \mathrm{d}$ ) but replacing the paracetamol with $10 \mathrm{MBq}^{99} \mathrm{Tc}^{\mathrm{m}}$-labelled tin colloid mixed into the cream. They did not, in study 2, go onto a low-fat diet for 5 weeks.

Gastric emptying was measured using a gamma camera interfaced to a computer (Tothill et al. 1978). Anterior and posterior computer images were acquired post-prandially every 15 min for $3 \cdot 5-4.5 \mathrm{~h}$. Geometric mean stomach counts were obtained for each image pair after correction for radioactive decay.

Plasma hormone and metabolite concentrations were measured as in study 1 ; in addition plasma motilin levels were measured by radioimmunoassay (Kwasowski, 1986). The sensitivity of the motilin assay was $42 \mathrm{ng} / 1$ and the interassay coefficient of variation $11 \%$.

Informed consent was given by all volunteers and the studies were approved by the ethical committee of St Luke's Hospital, Guildford, and the University of Surrey.

Results were compared using Student's $t$ test for paired values (two-tailed). Areas under the curve (AUC) were calculated using the trapezoidal rule. $P$ values of $<0.05$ were accepted as statistically significant.

\section{RESULTS}

Study 1

The mean daily fat and energy intakes of subjects whilst consuming their normal and lowfat diets are shown in Table 1 . Their mean weights fell slightly but not significantly during the low-fat-diet period (mean weight of subjects on normal diet 71.6 (SE 7.9) kg, after $35 \mathrm{~d}$ low-fat diet 68.9 (SE 7.9) kg, not significant).

There was no significant difference in fasting plasma glucose levels before and during the period on a low-fat diet. Plasma glucose levels remained unchanged at a mean basal level of $4.2 \mathrm{mmol} / 1$. During the oral fat with IV saline test (test meal 1) plasma glucose levels remained unchanged at a mean basal level of $4.2 \mathrm{mmol} / 1$ but rose sharply during the oral fat with IV glucose (test meal 2) to reach mean levels of $13.1 \mathrm{mmol} / 1$ in venous blood and $13.6 \mathrm{mmol} / \mathrm{l}$ in arterialized blood at $15 \mathrm{~min}$. Thereafter the blood glucose levels gradually fell in both venous and arterialized blood, reaching basal levels in venous blood by $120 \mathrm{~min}$.

Fasting plasma insulin levels were unchanged by the dietary modification. Following oral fat with IV saline (test meal 1) there was a small but significant rise in plasma insulin levels 


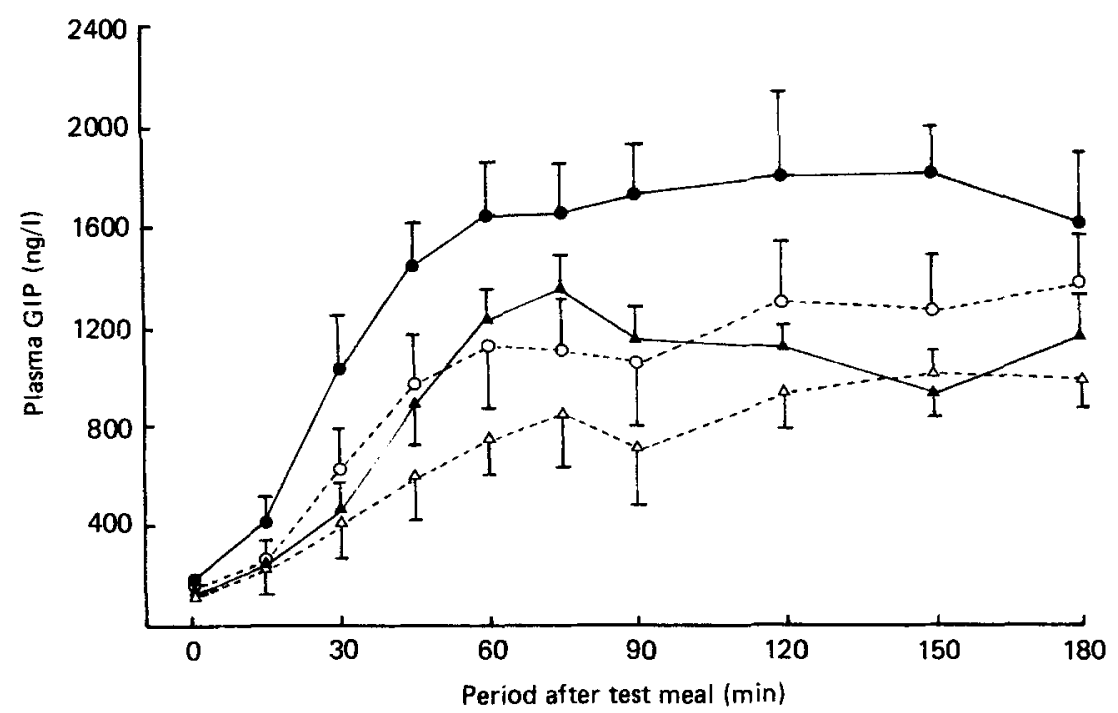

Fig. 1. Plasma gastric inhibitory polypeptide (GIP) concentrations in five healthy subjects following a $96 \mathrm{~g}$ fat test meal with intravenous (IV) glucose or saline before and $28 \mathrm{~d}$ following a low-fat diet. (O) Oral fat + IV saline, $(O)$ oral fat + IV glucose before low-fat diet. (A) Oral fat + IV saline, $(\triangle)$ oral fat + IV glucose following low-fat diet. Values are means with their standard errors represented by vertical bars.

Table 2. Effect of a low-fat diet on the incremental responses of plasma GIP, triglycerides, LSI and paracetamol to oral fat with and without intravenous (IV) glucose

(Mean values with their standard errors)

\begin{tabular}{|c|c|c|c|c|c|c|c|c|}
\hline & \multicolumn{8}{|c|}{ Incremental area under the curve, $0-180 \mathrm{~min}$} \\
\hline & \multicolumn{2}{|c|}{$\begin{array}{c}\text { GIP } \\
\text { (ng/l.h) }\end{array}$} & \multicolumn{2}{|c|}{$\begin{array}{c}\text { Triglycerides } \\
(\mathrm{mmol} / \mathrm{l} . \mathrm{h})\end{array}$} & \multicolumn{2}{|c|}{$\begin{array}{c}\text { LSI } \\
(\mathrm{U} / \mathrm{l} . \mathrm{h})\end{array}$} & \multicolumn{2}{|c|}{$\begin{array}{c}\text { Paracetamol } \\
(\mathrm{mmol} / 1 . \mathrm{h})\end{array}$} \\
\hline & Mean & $\mathrm{SE}$ & Mean & SE & Mean & $\mathrm{SE}$ & Mean & SE \\
\hline \multicolumn{9}{|l|}{ Normal diet } \\
\hline Fat + IV saline & $3906 * \ddagger$ & 523 & $2 \cdot 17+\S$ & 0.54 & $506+\S$ & 128 & $25 \cdot 2$ & $9 \cdot 15$ \\
\hline Fat + IV glucose & $2520^{*}$ & 555 & $0.69 \dagger \|$ & 0.22 & $227 \dagger \|$ & 67 & $15 \cdot 1 \|$ & $3 \cdot 42$ \\
\hline \multicolumn{9}{|l|}{ Low-fat diet } \\
\hline Fat + IV saline & $2332 \ddagger$ & 274 & $0 \cdot 40+8$ & 0.14 & $133 \S$ & 20 & 8.93 & 2.47 \\
\hline Fat + IV glucose & $1725^{+}$ & 383 & $0.14+\|$ & $0 \cdot 10$ & $93 \|$ & 23 & $6 \cdot 77 \|$ & $2 \cdot 10$ \\
\hline
\end{tabular}

GIP, Gastric inhibitory polypeptide; LSI, light-scattering index (an index of post-prandial chylomicronaemia).

* + Significant difference between fat + IV saline and fat + IV glucose test meals: $* P<0.01$ and $+P<0.025$ respectively.

I\$ Significant difference between normal and low-fat diet for fat + IV saline test meals: $\ddagger P<0.025$ and $\S P<0.0125$ respectively.

$\|$ Significant difference between normal and low-fat diet for fat + IV glucose test meals: $\| P<0.05$. 


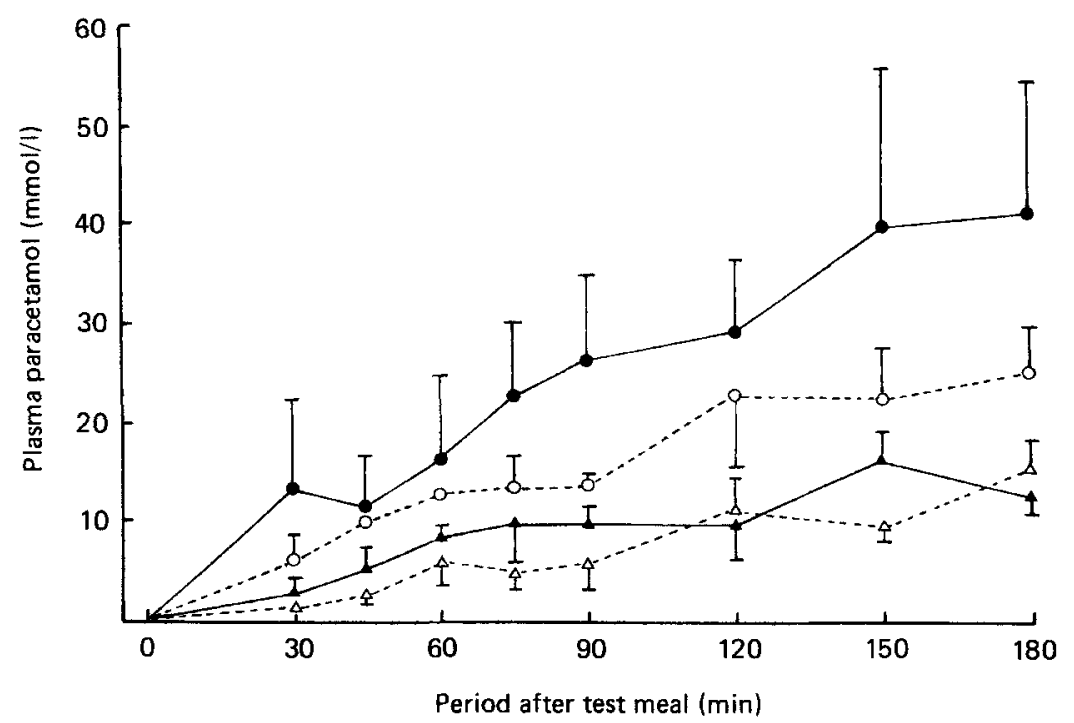

Fig. 2. Plasma paracetamol concentrations in five healthy subjects following a $96 \mathrm{~g}$ fat test meal with intravenous (IV) glucose or saline before and $28 \mathrm{~d}$ following a low-fat diet. (O) Oral fat + IV saline, (O) oral fat +IV glucose before low-fat diet. (A) Oral fat + IV saline, $(\triangle$ ) oral fat + IV glucose following low-fat diet. Values are means with their standard errors represented by vertical bars.

from a mean basal value of $6 \cdot 1(\mathrm{SE} 1 \cdot 0) \mathrm{mU} / 1$ to a mean peak level of $13 \cdot 1$ (SE 3.5) $\mathrm{mU} / 1$ $30 \mathrm{~min}$ after ingestion of the fat $(P<0.05)$. During test meal 2 (oral fat with IV glucose) mean plasma insulin levels rose to reach a peak value of 101 (SE 18.1) $\mathrm{mU} / 1$ after $45 \mathrm{~min}$. They then fell slowly to reach a mean level of 33.1 (SE 12) $\mathrm{mU} / 1$ at $180 \mathrm{~min}$, which was significantly lower than their peak levels $(P<0.001)$. The low-fat diet had no effect on the subjects' post-prandial plasma insulin levels for either test meal.

The GIP response to oral fat was significantly attenuated by substitution of IV glucose for saline (Fig. 1, Table 2) whilst the subjects were consuming their normal diet $(P<0 \cdot 01)$ and the GIP response to fat alone was significantly diminished during the low-fat diet compared with the normal diet $(P<0.025)$.

Plasma triglyceride levels and LSI paralleled the integrated GIP response on both normal and low-fat diets (Table 2). Fasting levels were unchanged by the period of dietary modification.

Changes in plasma paracetamol levels also paralleled the changes in plasma GIP levels. When tests were performed on subjects consuming their normal diet, plasma paracetamol levels were significantly lower during test meal 2 (fat with IV glucose) than during test meal 1 (fat with saline) at 75,150 and $180 \mathrm{~min}(P<0 \cdot 025)$, suggesting that IV glucose might have delayed gastric emptying (Fig. 2, Table 2).

\section{Study 2}

Plasma GIP, insulin, triglyceride and LSI levels were similar during each of the two test meals to those found in study 1 . IV glucose significantly attenuated the GIP response to oral fat $(P<0.025)$ and both plasma triglycerides and LSI were significantly lower when IV glucose rather than saline was infused $(P<0.025)$.

IV glucose almost doubled the gastric emptying time of the oral fat load calculated using ${ }^{99} \mathrm{Tc}^{\mathrm{m}}$ as a marker (Fig. 3). The half emptying time, $t_{\frac{1}{2}}$, was 148 (SE 11) min after fat alone and 224 (SE 18) $\min (P<0.005)$ for fat with IV glucose. 


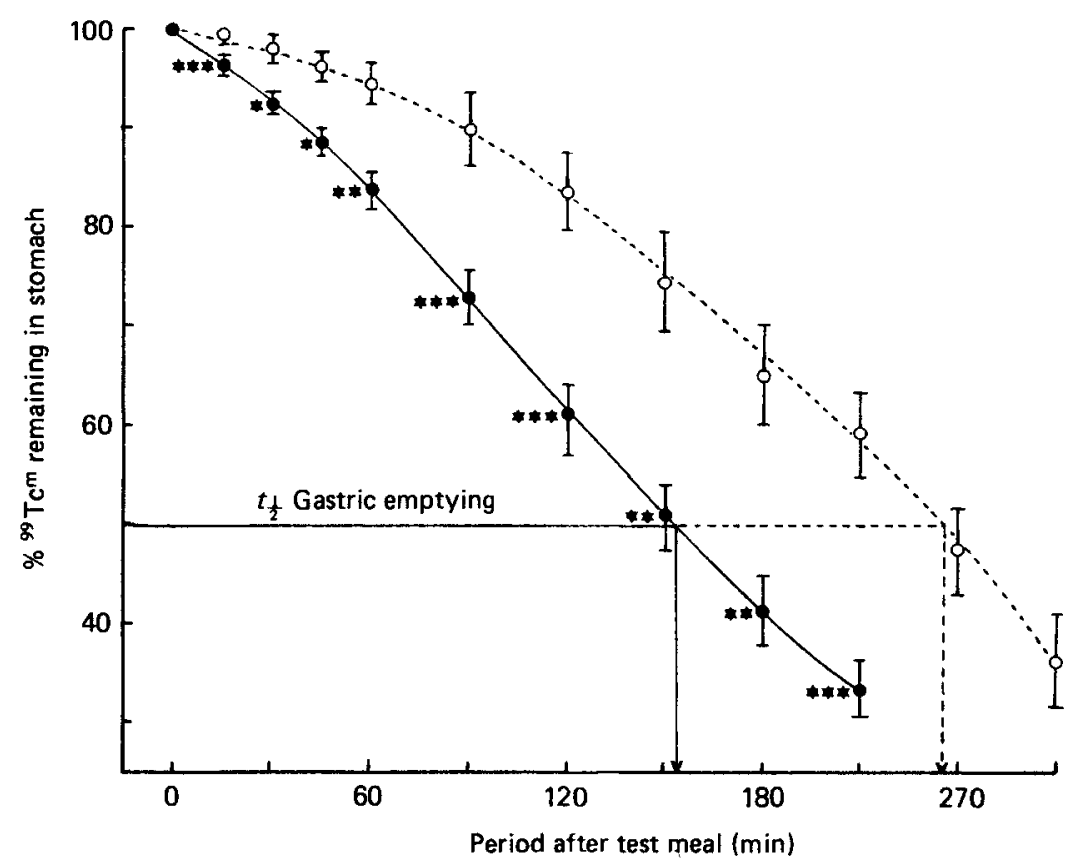

Fig. 3. Gastric emptying of ${ }^{99} \mathrm{Tc}^{\mathrm{m}}$-labelled tin colloid in seven healthy subjects following a $96 \mathrm{~g}$ fat test meal with either intravenous (IV) glucose or saline. (O) Oral fat + IV saline, (O) oral fat + IV glucose. Values are means with their standard errors represented by vertical bars. ${ }^{*} P<0.05,{ }^{* *} P<0.025$, *** $P<0.0005$. $t_{\frac{1}{a}}$, Half emptying time.

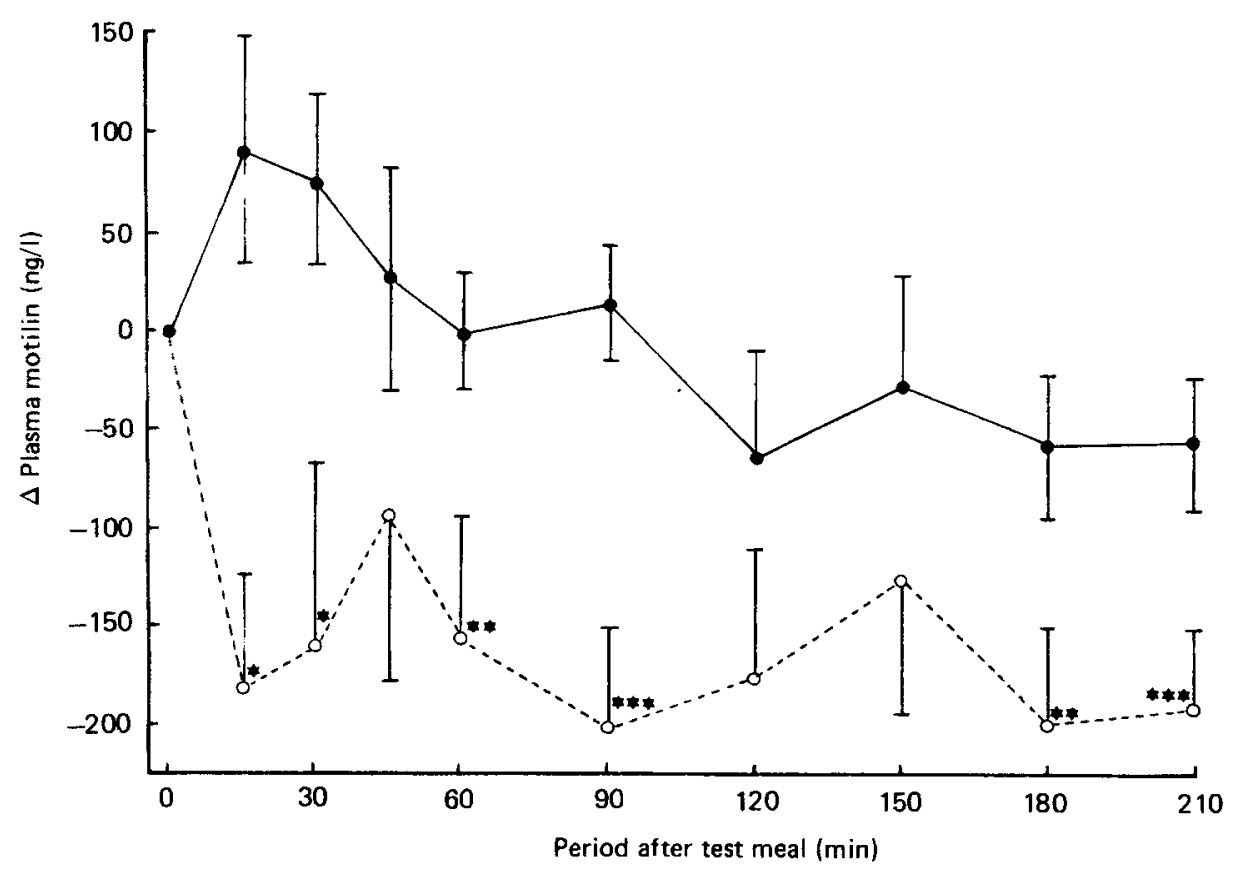

Fig. 4. Change in plasma motilin concentrations in seven healthy subjects following a $96 \mathrm{~g}$ fat test meal with either intravenous (IV) glucose or saline. (O) Oral fat + IV saline, $(O)$ oral fat + IV glucose. Values are means with their standard errors represented by vertical bars. ${ }^{*} P<0.05, * * P<0.0125$, *** $P<0.005$. 
Plasma motilin levels fell following oral fat with IV glucose, the falls reaching statistical significance at all time points except 20,45 and $150 \mathrm{~min}(P<0.025)$. Motilin levels were significantly lower than those during the fat with IV saline test meal at all time points except 45, 120 and $150 \mathrm{~min}(P<0.05)$ (Fig. 4).

\section{DISCUSSION}

Basal glucose, insulin and triglyceride levels were not significantly changed by a $35-\mathrm{d}$ period of fat restriction. Subjects reduced both fat and energy intake over the low-fat-diet period as it proved impracticable to achieve a substantial reduction in fat intake without a concommitant reduction in energy intake. There is little available information on the effect of fat and energy restriction on insulin and glucose levels in human subjects. Marked decreases in basal glucose, insulin and triglyceride levels have been demonstrated in a group of urbanized diabetic aborigines when they reverted to a traditional life-style with a lowfat, low-energy diet, but the changes were also accompanied by significant weight loss (O'Dea, 1984). Moreover, these subjects were initially obese and their hormone and metabolite levels were abnormally high.

The GIP response to oral fat was significantly diminished by the low-fat diet. Whilst it has been shown previously that exaggerated GIP responses to oral triglyceride in obese subjects can be reduced to near normal levels by 3 weeks of food restriction (Ebert et al. 1979), this is the first time that a reduction in GIP secretion in normal subjects has been demonstrated as a result of dietary manipulation. When subjects were consuming their normal diet, the GIP response to oral fat was significantly attenuated by IV glucose, consistent with previous reports (Cleator \& Gourlay, 1975; Ebert et al. 1979). However, the attenuation of GIP secretion by IV glucose was partially lost when the subjects were consuming a low-fat diet.

GIP secretion is dependent on absorption of nutrients (Creutzfeldt, 1979) and there is evidence that it is also related to their rate of absorption (Morgan et al. 1979). Postprandial levels of triglycerides and LSI paralleled post-prandial plasma GIP levels for all four test meals, suggesting that both the change in diet and the infusions of IV glucose had caused a change in the pattern of absorption of fat from the small intestine. Moreover, post-prandial plasma paracetamol levels also paralleled the plasma GIP responses to the test meals suggesting that altered gastric emptying may also be a factor in the attenuation of fat-stimulated GIP secretion both by IV glucose and by a low-fat diet. To verify the effect of IV glucose on gastric emptying, the oral fat with or without glucose protocol of the first study was repeated, replacing the paracetamol with ${ }^{99} \mathrm{Tc}^{\mathrm{m}}$-labelled tin colloid to assess gastric emptying by the more direct method of scintiscanning the stomach region. This confirmed that IV glucose almost doubled the gastric emptying time of the oral fat load. These findings are consistent with previous reports that acute hyperglycaemia induced by IV glucose delays the gastric emptying of a protein with a fat meal in man (MacGregor et $a l .1976 b$ ) and also suppresses trypsin secretion and bile salt output by means independent of its effect on gastric emptying (MacGregor et al. 1976a).

Both exogenous insulin (Brown et al. 1975) and intravenous glucose (Cleator \& Gourlay, 1975) have been found to diminish the GIP response to oral fat, leading to the proposal of a negative feedback between insulin and GIP (Brown et al. 1975). However, the prevailing level of hyperglycaemia has also been shown by Verdonck et al. (1980) to be important. In glucose-insulin clamp studies, GIP secretion in response to oral fat was shown to be both higher during a hypoglycaemic clamp and lower during a hyperglycaemic clamp than in euglycaemic clamp conditions (Verdonck et al. 1980). We have found in previous studies that the attenuation of fat-stimulated GIP secretion by exogenous insulin under 
hypoglycaemic conditions is very much smaller than is its attenuation by IV glucose, when hyperinsulinaemia occurs under hyperglycaemic conditions (Morgan et al. 1983). Whilst insulin has been shown by intraduodenal fat infusion studies to have a direct effect on suppressing fat-stimulated GIP secretion (Ebert et al. 1979; Stockmann et al. 1984) we have shown in the present study that delayed gastric emptying and alteration in fat absorption, whether as a direct consequence of changes in gastric emptying or from altered pancreatic and biliary secretion, is a factor which cannot be ignored in the diminished GIP response to oral fat when IV glucose is infused, irrespective of any direct action of insulin on GIP secretion.

The mechanism by which hyperglycaemia induces changes in gastric emptying remains speculative. We have shown that plasma motilin levels are suppressed when IV glucose is infused. Motilin has been shown to stimulate contraction of the stomach and also to affect intestinal motility (Brown et al. 1971). It is the gastrointestinal hormone most likely to play a physiological role in altering gut motility, and hence the rate of absorption of nutrients, and it is possible that the changes observed with IV glucose are mediated via changes in motilin.

GIP has been shown to be an important factor in stimulating insulin secretion in both normal and pathological states. The demonstration that its secretion is modified by both dietary changes and hyperglycaemia, whatever the mechanism involved, could be important in determining the degree of hyperinsulinaemia which occurs following a meal, its modification by dietary changes, and consequent association with the pathology of various hyperinsulinaemic states in which dietary factors also play a part. However, the factors controlling GIP secretion are complex and the present study shows that caution must be exercised in their interpretation in the light of the observed changes in gastric emptying.

REFERENCES

Brown, J. C., Dryburgh, J. R., Ross, S. A. \& Dupre, J. (1975). Recent Progress in Hormone Research 31, 487-532.

Brown, J. C., Mutt, V. \& Dryburgh, J. R. (1971). Canadian Journal of Physiology 49, 399-405.

Cleator, J. G. M. \& Gourlay, R. H. (1975). American Journal of Surgery 130, 128-135.

Creutzfeldt, W. (1979). Diabetologia 16, 75-85.

Ebert, R. \& Creutzfeldt, W. (1987). Canadian Journal of Physiology and Pharmacology 64 (7), 100.

Ebert, R., Frerichs, H. \& Creutzfeldt, W. (1979). European Journal of Clinical Investigation 9, 129-135.

Ebert, R., Willms, B., Brown, J. C. \& Creutzfeldt, W. (1976). European Journal of Clinical Investigation 6, 327.

Gamble, P. R., Gentry, R. \& Kipps, M. (1980). Superdiet Dietary Analysis Programme. Guildford: University of Surrey.

Hampton, S. M., Kwasowski, P., Tan, K., Morgan, L. M. \& Marks, V. (1983). Diabetologia 24, $278-281$.

Holt, S., Heading, R. C., Carter, D. C., Prescott, L. F. \& Tothill, P. (1979). Lancet i, 636-639.

Kwasowski, P. (1986). GIP, an intestinal metabolic hormone. PhD thesis, University of Surrey.

MacGregor, I. L., Deveney, C., Way, L. W. \& Meyer, J. M. (1976a). Gastroenterology 70, 197-202.

MacGregor, I. L., Gueller, R., Watts, H. D. \& Meyer, J. M. (1976b). Gastroenterology 70, 190-196.

Metropolitan Life Insurance Company (1959). Statistical Bulletin 40, Nov.-Dec.

Morgan, L. M., Goulder, T., Tsiolakis, D., Marks, V. \& Alberti, K. (1979). Diabetologia 17, 1-5.

Morgan, L. M., Hampton, S. M., Tredger, J. A., Dedman, L., Cramb, R. \& Marks, V. (1984). Digestive Diseases and Sciences 29, 55.

Morgan, L. M., Morris, B. A. \& Marks, V. (1978). Annals of Clinical Biochemistry 15, 172-177.

Morgan, L. M., Tredger, J. A., Hampton, S. M., Kwasowski, P., Wright, J., Dunn, M. \& Marks, V. (1983). Scandinavian Journal of Gastroenterology 18, Suppl. 87, 99-101.

National Advisory Committee on Nutrition Education (1983). A Discussion Paper on Proposals for Nutritional Guidelines for Health Education in Britain, London: Health Education Council

O'Dea, K. (1984). Diabetes 33, 596-603.

Stockmann, F., Ebert, R. \& Creutzfeldt, W. (1984). Diabetes 33, 580-585. 
Stout, R. (1982). International Journal of Obesity 6, 111-115.

Tothill, P., McLoughlin, G. P. \& Heading, T. C. (1978). Journal of Nuclear Medicine 19, 256-261.

Verdonk, C. A., Rizza, R. A., Nelson, R. L., Go, V. L. W. \& Gerich, J. E. (1980). Journal of Clinical Investigation 65, $1119-1125$.

Willms, B., Ebert, R. \& Creutzfeldt, W. (1978). Diabetologia 14, 379-387. 